British Journal of Psychiatry (1990), 157, 294-303

\title{
Correspondence
}

Editor: Ian Pullen

Contents: The 'new cross-cultural psychiatry'/Impact of participating in research/Genital self-mutilation/ Psychiatric sequelae of listeriosis/Aggressiveness, anxiety and drugs/Limitations of double-blind trials/ Reviewing reviewers/ROC analysis/The Lomax affair/Brain transplants: myth or monster?/Patterns of attendance at child psychiatry clinics/First-rank symptoms

\section{The 'new cross-cultural psychiatry'}

SIR: In his editorial on the 'new cross-cultural psychiatry', Leff's assertion (Journal, March 1990, 156, 305-307) that the disease categories of Western biomedicine are universally valid is mistaken, and his statement about its "manifest success in treating diseases like smallpox" is difficult to sustain in light of the evidence provided by disciplines including medical sociology, anthropology and the history of medicine. Research in these areas points to the particular and ultimately ethnocentric nature of all medical classifications. The positivist notion of medicine as a set of technical interventions divorced from social, political and cultural influences is surely untenable in the late 20th century. That medicine is rather a social institution and functions as such in every society, be it in Africa or Europe, is now widely accepted.

The success of any medical classification has to be seen in this context. The criteria used by Western medicine to judge its own performance are provided by the institutional framework within which it operates. The eradication of smallpox only proves the "manifest success" of Western biomedicine within the confines of a Western ontology and world-view. In addition, if medicine is not simply a set of techniques but rather a social institution, the evaluation of its efforts is a lot more complicated than Leff supposes. For example, in the Kasongo vaccination project in Zaire (Kasongo Project Team, 1981), while a high coverage of measles immunisations was achieved and led to a noticeable reduction in measles mortality, the overall mortality was not affected. The same number of children perished, but from other causes. Was the medical intervention successful? By what criteria do we judge?
Some time ago, Illich (1976) argued that if we look at Western biomedicine as an institution and examine its social and cultural effects in Western countries, we are led to the conclusion that its overall impact is one of iatrogenesis. While one may not agree fully with Illich's conclusions, his work should make us wary of statements about the "manifest success" of Western biomedicine.

The 'new cross-cultural psychiatry' as presented by Littlewood (Journal, March 1990, 156, 308-327) opens the way for the development of a discipline which is genuinely self-reflective and which confronts the ethnocentric nature of our current systems. However, if we continue to pursue an approach based on positivist biomedicine, we are simply ignoring this ethnocentricity, which is ultimately the real problem of our discipline. It will not go away. Aspiring to the "manifest success" of biomedicine should surely not be the goal of psychiatry in the 1990s.

PATRICK J. BRACKEN JoAN E. Giller

PO Box 269

Kampala

Uganda

\section{Roferences}

Iluch, I. (1976) Limits to Medicine-Medical Nemesis: The Expropriation of Health. Harmondsworth: Pelican.

KAsongo Project Tram (1981) Influence of measles vaccination on survival pattern of 7-35 month old children in Kasongo, Zaire. Lancet, ii, 764 .

SIR: Leff(Journal, March 1990, 156, 305-307) offers a captious view of Littlewood's review of the 'new cross-cultural psychiatry' (Journal, March 1990, 156, 308-327). For instance, Leff cites Littlewood's (1984) paper which, contrary to Leff's interpretation, neither idealises nor romanticises insanity, but rather demonstrates how intellectual innovation can arise from a particular society's reponse to the inversion of normal behaviour by two messianic leaders who experienced episodes of psychosis.

Dr Littlewood's review includes some suggestions on how clinically applied anthropology can, for example, enhance the role of the liaison psychiatrist 
on psychosomatic wards. This is hardly a Laingian anti-psychiatry enterprise.

Professor Leff fails to do justice to the important conceptual and practical innovations offered by Kleinman (1988). These include the systematic creation of an ethnography of each patient's experience of illness and his or her "explanatory model"; a recognition of the culture-bound nature of the idioms of distress used by laymen to indicate dysphoria; and a heightened awareness of psychiatry's own cultural origins and tacit assumptions and its tendency to systematically minimise cultural differences in the symptoms and interpretation of mental illness.

MAURICE LIPSEDGE

Guy's Hospital

St Thomas Street

London SE1 9RT

\section{References}

Kuetnman, A. (1988) Rethinking Psychiatry: From Cultural Category to Personal Experience. New York: Free Press.

LITTLWOOD, R. (1984) The imitation of madness: the influence of psychopathology upon culture. Social Science and Medicine, 19, 705-715.

SIR: Leff (Journal, March 1990, 156, 305-307) gives the wrong impression about what anthropologicallyorientated studies in psychiatry are all about.

Professor Leff uses the example of smallpox to criticise an epistemological approach to psychiatry, which he appropriately associates with anthropological works on psychiatry, yet inappropriately implies is a continuation of nihilistic anti-psychiatry. For Professor Leff, vaccination, which Jenner developed from 18th-century English folk beliefs, was successful in eradicating smallpox; Yoruba and Hindu ethnotheories about this disease, however, were not effective and therefore, unlike biomedical categories, did not become dominant. Although his intended meaning is unclear here, especially since he qualifies his argument with examples where success is greater for indigenous therapies of Third World societies, Professor Leff seems to imply a utilitarian justification of psychiatric categories.

This is a strange conclusion to draw from the smallpox case for several reasons. The World Health Organization's (WHO's) eradication campaign was a logistic, administrative and political triumph which drew upon knowledge of local cultures and the WHO's own institutional culture to overcome obstacles, some of which derived from contemporary public health policies. Furthermore, as Marglin (1988) indicates, the eradication of smallpox in the Indian subcontinent had some ironic twists. The traditional Indian practice of variolation, which had a certain measure of efficacy, was outlawed by the British government in India in 1865, and this both worsened the public health situation and contributed to the colonial policy of fostering Indian dependence in the sphere of health. Later on during British rule, the popular resistance to the compulsory vaccinations introduced in some provinces was a surrogate for more widespread political resistance and led to a worsening of the smallpox problem. Moreover, the forced vaccinations in the 1960s and 1970s, which ultimately eradicated smallpox, produced such resistance that its after-effects still reverberate, causing obstacles to public health programs. It was not biomedical categories, then, but cultural values and political interests which fostered both the successes and negative consequences of smallpox eradication campaigns.

The beliefs, rituals and community activities in honour of Sitala - the smallpox goddess - are associated with "their ability to regenerate the community, to create or re-create social consequences" (Marglin, 1988, p. 7) and are part of a Hindu view of health as the result of the experience of illness and death, and not as their opposite or enemy. Seen from the perspective of how Indian culture responds to neardeath experiences of the aged and the chronically ill, the Hindu conception may be more successful, at least with respect to these experiences, than its biomedical counterpart.

The anthropological approach to psychiatry begins with cultural epistemology because this is useful to understand the indigenous or lay beliefs about illness and how these constrain treatment decisions. Anthropological investigations also show how a health problem is constructed as a technical/ professional problem through the application of diagnostic categories and clinical assessment methodologies, and how this creates an 'object' of psychiatric practice. Biomedical categories strip away the illness experience, including the moral condition of suffering, to get at disease pathology. When that reduction is successful, as is the case with many treatable acute infectious diseases, it is an example of a remarkably useful cultural bias. When it is relatively unsuccessful, which is often the case in chronic medical and psychiatric conditions, the outcome is a form of dehumanised care and also an impoverished scientific epistemology for medicine/psychiatry.

In my book (Kleinman, 1988), I tried to show how an epistemological approach to psychiatric practice can be a useful method for uncovering and remedying serious biases in our taxonomies, value hierarchies and treatment practices that limit our discipline's utility in developed and developing societies. The 